\title{
STABILITY RESULTS FOR ONE-STEP DISCRETIZED COLLOCATION METHODS IN THE NUMERICAL TREATMENT OF VOLTERRA INTEGRAL EQUATIONS
}

\author{
M. R. CRISCI, E. RUSSO, AND A. VECCHIO
}

\begin{abstract}
This paper is concerned with the stability analysis of the discretized collocation method for the second-kind Volterra integral equation with degenerate kernel. A fixed-order recurrence relation with variable coefficients is derived, and local stability conditions are given independent of the discretization. Local stability and stability with respect to an isolated perturbation of some methods are proved. The reliability of the derived stability conditions is shown by numerical experiments.
\end{abstract}

\section{INTRODUCTION}

We consider the second-kind Volterrra integral equation

$$
y(t)=g(t)+\int_{t_{0}}^{t} k(t, s, y(s)) d s, \quad t \in\left[t_{0}, T\right],
$$

where $g$ and $k$ are given continuous functions on $\left(t_{0}, T\right)$ and $S \times R$, respectively, with $S=\left\{(t, s): t_{0} \leq s \leq t \leq T\right\}$. Let

$$
\Pi_{N}: t_{0}<t_{1}<\cdots<t_{N}=T
$$

denote a partition of the integration range, with $t_{i+1}-t_{i}=h$, and let $0 \leq$ $c_{1}<c_{2}<\cdots<c_{m} \leq 1$ be $m$ parameters. The one-step discretized collocation method $[4,9]$ (hereafter referred to as VDC) approximates the solution $y(t)$ of (1.1) by a spline function $u(t)$ defined by

$$
u\left(t_{i}+s h\right)=\sum_{k=1}^{m} L_{k}(s) u_{i k}, \quad s \in[0,1]
$$

where

$$
L_{k}(s)=\prod_{\substack{j=1 \\ j \neq k}}^{m}\left(s-c_{j}\right) /\left(c_{k}-c_{j}\right)
$$

and the $u_{i k}$ are solutions of the system

$$
u_{i j}=g\left(t_{i j}\right)=\Psi_{j}^{i}+\phi_{j}^{i}, \quad j=1, \ldots, m,
$$

Received July 26, 1988; revised October 19, 1989, October 24, 1990.

1991 Mathematics Subject Classification. Primary 65R20; Secondary 45D05, 45L10.

Key words and phrases. Volterra integral equations, degenerate kernel, stability, discrete collocation methods, Runge-Kutta methods. 
where $t_{i j}=t_{i}+c_{j} h$ and $\psi_{j}^{i}, \phi_{j}^{i}$ are quadrature sums approximating

$$
\int_{t_{0}}^{t_{i}} k\left(t_{i j}, s, u(s)\right) d s \text { and } \int_{t_{i}}^{t_{i j}} k\left(t_{i j}, s, u(s)\right) d s,
$$

respectively. Following [9] (to which the reader is referred to for more details), the most common choices for $\psi_{j}^{i}$ and $\phi_{j}^{i}$ are

(a)

$$
\begin{gathered}
\Psi_{j}^{i}=h \sum_{\nu=0}^{i-1} \sum_{k=1}^{m-\vartheta} w_{k} k\left(t_{i j}, t_{\nu k}, u_{\nu k}\right), \\
\phi_{j}^{i}=h \sum_{k=1}^{m-\vartheta} w_{j k} k\left(t_{i j}, t_{i k}, u_{i k}\right),
\end{gathered}
$$

where

$$
\begin{gathered}
w_{k}=\int_{0}^{1} L_{k}(s) d s, \quad k=1, \ldots, m, \\
w_{j k}=\int_{0}^{c_{j}} L_{k}(s) d s, \quad k, j=1, \ldots, m, \\
\vartheta= \begin{cases}0 & \text { for the "implicit discretization," } \\
1 & \text { for the "discretization using m - 1 points," } \\
j-1 & \text { for the "explicit discretization," } \\
j & \text { for the "diagonally explicit discretization." }\end{cases}
\end{gathered}
$$

(b)

"Fully implicit discretization": the $\psi_{j}^{i}$ given by (1.5) with $\vartheta=0$,

$$
\phi_{j}^{i}=h \sum_{k=1}^{m} c_{j} w_{k} k\left(t_{i j}, t_{i}+c_{j} c_{k} h, \sum_{\nu=1}^{m} L_{\nu}\left(c_{j} c_{k}\right) u_{i \nu}\right),
$$

so that the kernel $k$ is computed only in $S$.

VDC methods, until now, have been studied mainly with regard to convergence order $[4,7,8]$, and less so with regard to stability properties. In [10] and [11] we analyzed stability of the exact collocation method by applying it to the basic and the convolution test equation, and to the second-kind integral equation with degenerate kernel, respectively. Here we perform the stability analysis of the VDC method for a linear second-kind integral equation with degenerate kernel of rank $n[3,5]$,

$$
y(t)=g(t)+\int_{t_{0}}^{t} \sum_{l=1}^{n} a_{l}(t) b_{l}(s) y(s) d s, \quad t \in\left[t_{0}, T\right] .
$$

From the Stone-Weierstrass theorem it follows that the class of degenerate kernels,

$$
k(t, s)=\sum_{l=1}^{n} a_{l}(t) b_{l}(s)
$$


is dense in the class of all continuous kernels, so that (1.10) can be considered a significant test equation for stability analysis.

Conditions ensuring the stability of the analytical solution of (1.1) are given in $[1,5,9]$.

In order to analyze the stability properties of VDC methods, a finite-length recurrence relation is constructed in $\S 2$ for a vector containing the numerical solution. This recursion is then used to prove local stability conditions. The conditions obtained are independent of the kernel decomposition and require the localization of the roots of a polynomial whose degree is the minimum of the rank of the kernel and the number of the collocation points. In the particular case of the degenerate convolution kernel, the above conditions are shown to furnish a priori stability conditions. In $\S 3$, conditions for the stability of the trapezoidal rule are given. Then, for particular degenerate kernels, a class of VDC methods is determined, including those whose collocation parameters are the Legendre and Radau points, which satisfy the local stability conditions, and a bound for $h$ is found which ensures the bounded propagation of an isolated perturbation in these methods. Finally, in $\S 5$, numerical results are reported, showing the reliability of the stability conditions derived.

\section{RECURRENCE RELATION AND LOCAL STABILITY CONDITIONS}

In this section, stability theorems are derived for the VDC method applied to the second-kind Volterra integral equation with degenerate kernel (1.10). These theorems are independent of the choice of discretizations, such as those suggested in $\S 1$. The results obtained are analogous to those derived for the exact collocation method in [11], and since they are based on the same technique, only a short outline of the proofs is given.

First we derive a finite-length recurrence relation for the method. To do so, we set

$$
\alpha_{j k}^{i}=a_{k}\left(t_{i j}\right), \quad j=1, \ldots, m, k=1, \ldots, n, \quad A^{i}=\left[\alpha_{j k}^{i}\right] .
$$

In correspondence to the chosen quadrature formulae (1.6), (1.9) we denote by $z_{j}^{i}$ a quadrature sum for the integral $\int_{t_{0}}^{t_{i}} b_{j}(s) u(s) d s$ and we set

$$
\begin{aligned}
s_{j k}^{i} & = \begin{cases}w_{j k} k\left(t_{i j}, t_{i k}\right), & k=1, \ldots, m-\vartheta, j=1, \ldots, m \\
0 & \text { for the discretization }(\mathbf{a}), \\
c_{j} w_{k} \sum_{\nu=1}^{m} k\left(t_{i},\right. & k=m-\vartheta+1, \ldots, m, j=1, \ldots, m, \\
\left.t_{i}+c_{j} c_{\nu} h\right) L_{k}\left(c_{j} c_{\nu}\right), & j, k=1, \ldots, m, \text { for the discretization (b), }\end{cases} \\
S^{i}=\left(s_{j k}^{i}\right), & \\
\beta_{j k}^{i} & = \begin{cases}w_{k} b_{j}\left(t_{i k}\right), & k=1, \ldots, m-\vartheta, j=1, \ldots, n, \\
0, & k=m-\vartheta+1, \ldots, m, j=1, \ldots, n,\end{cases} \\
B^{i} & =\left(\beta_{j k}^{i}\right) .
\end{aligned}
$$

Let $I_{k}$ be the identity matrix of order $k$ and

$$
\begin{gathered}
v_{i}=\left[u\left(t_{i}\right), u_{i-1,1}, \ldots, u_{i-1, m}, z_{1}^{i}, \ldots, z_{n}^{i}\right]^{\mathrm{T}}, \\
g_{i}=\left[g\left(t_{i 1}\right), \ldots, g\left(t_{i m}\right)\right]^{\mathrm{T}},
\end{gathered}
$$




$$
\begin{gathered}
L=\left[L_{1}(1), \ldots, L_{m}(1)\right]^{\mathrm{T}}, \\
M_{0}^{i}=\left[\begin{array}{ccc}
1 & -L & 0 \\
0 & I_{m}-h S^{i} & 0 \\
0 & -h B^{i} & I_{n}
\end{array}\right], \quad M_{1}^{i}=\left[\begin{array}{ccc}
0 & 0 & 0 \\
0 & 0 & A^{i} \\
0 & 0 & I_{n}
\end{array}\right] .
\end{gathered}
$$

Then the following theorem holds.

Theorem 2.1. The application of the VDC method to a second-kind Volterra integral equation with degenerate kernel leads to the finite-length recurrence relation

$$
M_{0}^{i} v_{i+1}-M_{1}^{i} v_{i}=\left(\begin{array}{c}
0 \\
g_{i} \\
0
\end{array}\right) .
$$

Proof. The proof is outlined only for the case of the implicit discretization. Using the above notations, we have

$$
\psi_{j}^{i}=\sum_{l=1}^{n} a_{l}\left(t_{i j}\right) z_{l}^{i},
$$

and the assertion follows from (1.2) and (1.4) by observing that in the case considered, $z_{l}^{i}$ satisfies

$$
z_{l}^{i+1}=z_{l}^{i}+h \sum_{k=1}^{m} w_{k} b_{l}\left(t_{i k}\right) u_{i k}
$$

Remark 2.1. In the particular case of the polynomial convolution kernel, it can be shown by tedious algebraic manipulations that the recurrence formula (2.7) reduces to the recursion derived in [2] for an extended Runge-Kutta method.

From the applicability of the method it follows that $I_{m}-h S^{i}$ is invertible, so that (2.7) can be written as

$$
v_{i+1}=M^{i} v_{i}+\rho_{i}
$$

where

$$
\rho_{i}=\left(\begin{array}{c}
0 \\
\left(I_{m}-h S^{i}\right)^{-1} g_{i} \\
h B^{i}\left(I_{m}-h S^{i}\right) g_{i}
\end{array}\right),
$$

and the stability matrix is given by

$$
M^{i}=\left(M_{0}^{i}\right)^{-1}\left(M_{1}^{i}\right)=\left[\begin{array}{ccc}
0 & 0 & L\left(I_{m}-h S^{i}\right)^{-1} A^{i} \\
0 & 0 & \left(I_{m}-h S^{i}\right)^{-1} A^{i} \\
0 & 0 & h B^{i}\left(I_{m}-h S^{i}\right)^{-1} A^{i}+I_{n}
\end{array}\right] .
$$

Since the elements of $M^{i}$ depend on the step number $i$, it is possible to derive conditions only for local stability $[9$, p. 432].

Put

$$
D^{i}=I_{n}+h B^{i}\left(I_{m}-h S^{i}\right)^{-1} A^{i} .
$$

Then the following theorem can be established. 
Theorem 2.2. The VDC method is

(i) locally stable in the strong sense if all eigenvalues of $D^{i}$ are inside the unit circle;

(ii) locally stable if the eigenvalues of $M^{i}$ are inside the unit circle and those on the boundary are weakly stable, i.e., the corresponding Jordan blocks are of order 1 .

Remark 2.2. When $h \rightarrow 0$, the matrix $D^{i} \rightarrow I$, and hence the VDC method is locally stable as $h \rightarrow 0$.

Defining the matrix

$$
F(x)=(x-1)\left(I_{m}-h S^{i}\right)-h A^{i} B^{i}
$$

and the polynomial

$$
C(x)=\operatorname{det}[F(x)],
$$

we can easily prove the following theorem.

Theorem 2.3. The VDC method is locally stable in $t_{i}$ in the strong sense if all zeros of

$$
(x-1)^{n-m} C(x)=0
$$

are inside the unit circle; it is locally stable if they are inside or on the unit circle and those on the unit circle correspond to weakly stable eigenvalues of $\mathbf{M}^{i}$.

Remark 2.3. In the case of the implicit and fully implicit discretization, which are the most common, the polynomial $C(x)$ does not depend on the kernel decomposition. In fact, the $(j, k)$ element of the matrix $F(x)$ defined in (2.13) can be written as

$$
f_{j k}=(x-1)\left(\delta_{j k}-h s_{j k}^{i}-h w_{k} k\left(t_{i j}, t_{i k}\right)\right),
$$

and so the stability conditions derived from the above theorem can be applied under the only hypothesis that the kernel is separable, even if the decomposition is unknown.

Remark 2.4. The calculation of the $n$ eigenvalues of (2.12) is reduced to the determination of the roots of a polynomial whose degree is the minimum of $n$ and $m$.

Corollary 2.1. If $n>m$, then the VDC method is not locally stable in the strong sense.

Theorem 2.4. If $n>m$ and $\operatorname{det}\left(A^{i} B^{i}\right) \neq 0$, then the VDC method is locally stable in $t_{i}$ when all the zeros of $C(x)$ are inside the unit circle.

Theorem 2.5. If $k(t, s)$ is a convolution degenerate kernel, then the eigenvalues of the matrix $M^{i}$ do not depend on $i$.

Note that for this kernel, Theorem 2.3 yields a priori stability conditions.

Remark 2.5. We recall [9] that if $c_{m}=1$, then the VDC method is equivalent to an extended Pouzet Runge-Kutta method for the discretization (a), and to a 
de Hoog and Weiss Runge-Kutta method for the discretization (b). Therefore, all theorems so far stated are valid also for these Runge-Kutta methods.

\section{STABILITY THEOREMS FOR THE IMPLICIT DISCRETIZATION METHOD}

This section is concerned with stability properties of the VDC method applied to equation (1.10). We first deal with the particular case of two collocation parameters $c_{1}=0, c_{2}=1$. For such methods the discretizations of kind (a) and (b) coincide; moreover, the VDC method is equivalent to the trapezoidal rule.

The following theorem holds.

Theorem 3.1. The trapezoidal rule is locally stable in $t_{i}$ if and only if each of the following three conditions holds:

(i) $k\left(t_{i}, t_{i}\right) k\left(t_{i+1}, t_{i+1}\right)-k\left(t_{i}, t_{i+1}\right) k\left(t_{i+1}, t_{i}\right)>0$;

(ii) $k\left(t_{i+1}, t_{i+1}\right)+k\left(t_{i}, t_{i}\right)<0$;

(iii)

$$
\begin{aligned}
& 4+h k\left(t_{i}, t_{i}\right)-h k\left(t_{i+1}, t_{i+1}\right) \\
& \quad-h^{2} / 4\left[k\left(t_{i}, t_{i}\right) k\left(t_{i+1}, t_{i+1}\right)-k\left(t_{i}, t_{i+1}\right) k\left(t_{i+1}, t_{i}\right)\right]>0 .
\end{aligned}
$$

Proof. The theorem is easily proved by applying Theorem 2.3 and the RouthHurwitz conditions to the coefficients of the second-degree polynomial $C(x)$ given in (2.14).

From Theorem 3.1, the following corollaries can be readily obtained. Let

$$
\gamma=\max _{i} \sup _{(t, s) \in\left[t_{i}, t_{i+1}\right]^{2}}|k(t, s)| .
$$

Corollary 3.1. If conditions (i) and (ii) of the previous theorem hold, then the trapezoidal rule is locally stable in $t_{i}$ for $h \gamma<1$.

Corollary 3.2. If the kernel $k(t, s)$ is of convolution type, $k(t, s)=k(t-s)$, and if conditions (i) and (ii) hold, then the trapezoidal rule is locally stable in each $t_{i}$ if

$$
h<4 / \sqrt{k(0)^{2}-k(h) k(-h)} .
$$

We now present some results which will be useful later. Define the following matrix:

$$
\Gamma(t)=\left(\gamma_{j k}\right)=\left(a_{k}(t) b_{j}(t)\right), \quad j, k=1, \ldots, n,
$$

and vector:

$$
P(t)=\left[b_{1}(t) g(t), \ldots, b_{n}(t) g(t)\right]^{\mathrm{T}} .
$$

It is known that the solution $y(t)$ of the integral equation (1.10) can be written as

$$
y(t)=\sum_{k=1}^{n} a_{k}(t) z_{k}(t),
$$

where the vector $z(t)=\left[z_{1}(t) \cdots z_{n}(t)\right]^{\mathrm{T}}$ is the solution of the associated differential system:

$$
\begin{gathered}
z^{\prime}(t)=\Gamma(t) z(t)+P(t), \\
z\left(t_{0}\right)=0 .
\end{gathered}
$$


Theorem 3.2. The differential system (3.2) is dissipative with respect to the Euclidean norm if and only if a function $f(t)>0$ on $\left[t_{0}, \infty\right)$ exists such that $a_{k}(t)=-f(t) b_{k}(t), k=1, \ldots, n$.

Proof. The condition is sufficient, as it can be proved by a trivial extension of Theorem 3.4 in [1]. It is also necessary; in fact, if the system (3.2) is dissipative with respect to the Euclidean norm, the eigenvalues of $\frac{1}{2}\left(\Gamma+\Gamma^{\mathrm{T}}\right)$ are negative or equal to 0 . These eigenvalues are 0 (of multiplicity $n-2$ ) and

$$
\begin{aligned}
& \chi_{1}=\sum_{l=1}^{n} a_{l}(t) b_{l}(t)+\sqrt{\sum_{l=1}^{n} a_{l}^{2}(t) \sum_{l=1}^{n} b_{l}^{2}(t)}, \\
& \chi_{2}=\sum_{l=1}^{n} a_{l}(t) b_{l}(t)-\sqrt{\sum_{l=1}^{n} a_{l}^{2}(t) \sum_{l=1}^{n} b_{l}^{2}(t)} .
\end{aligned}
$$

The assertion now follows from the Cauchy-Schwarz inequality.

Definition 3.1. The degenerate kernel (1.11) is of class $A$ if it satisfies the following conditions:

(i) There exist $p, q$ such that $1 / p+1 / q=1$ and

$$
\left(\sum_{l=1}^{n}\left|a_{l}(t)\right|^{p}\right)^{1 / p} \int_{t_{0}}^{t}\left(\sum_{l=1}^{n}\left|b_{l}(s)\right|^{q}\right)^{1 / q} d s<\infty .
$$

(ii) There exists a function $f(t)>0$ on $\left[t_{0}, \infty\right)$ such that

$$
a_{l}(t)=-f(t) b_{l}(t), \quad l=1, \ldots, n .
$$

From Theorem 3.2 and the results in [2] it follows that integral equations with kernel of class $A$ are stable.

A VDC method with implicit discretization can be written in compact form using the "Butcher array"

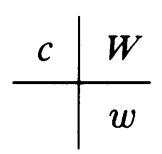

where the elements of $W$ and $w$ are defined in (1.8) and (1.7), respectively.

Definition 3.2. A VDC method and a Runge-Kutta method for ordinary differential equations characterized by the same Butcher array are said to be "corresponding."

Then we can prove:

Theorem 3.3. $A$ VDC method corresponding to an algebraically stable RungeKutta method is, on kernels of class $A$, locally stable in each $t_{i}$ and for each stepsize $h$.

Proof. Setting

$$
z_{l j}^{i}=z_{l}^{i}+h \sum_{k=1}^{m} w_{j k} b_{l}\left(t_{i k}\right) u_{i k}
$$


we can write $(2.8)$ as

$$
\begin{aligned}
& z_{l}^{i}=z_{l}^{i}+h \sum_{k=1}^{m} w_{k} b_{l}\left(t_{i k}\right)\left[g\left(t_{i k}\right)+\sum_{r=1}^{n} a_{r}\left(t_{i k}\right) z_{r k}^{i}\right], \quad l=1, \ldots, n, \\
& z_{l j}^{i}=z_{l}^{i}+h \sum_{k=1}^{m} w_{j k} b_{l}\left(t_{i k}\right)\left[g\left(t_{i k}\right)+\sum_{r=1}^{n} a_{r}\left(t_{i k}\right) z_{r k}^{i}\right], \\
& l=1, \ldots, n, \quad j=1, \ldots, m .
\end{aligned}
$$

This can be viewed as the corresponding Runge-Kutta method applied to the dissipative system (3.2) with initial conditions $z_{j}\left(t_{i}\right)=z_{j}^{i}, j=1, \ldots, n$.

With $Z_{i}=\left[z_{1}^{i}, \ldots, z_{n}^{i}\right]$, it follows from the algebraic stability of the RungeKutta methods that

$$
\left\|Z_{i+1}-Z_{i+1}^{*}\right\|_{2} \leq\left\|Z_{i}-Z_{i}^{*}\right\|_{2} \text { for every } Z_{i}, Z_{i}^{*},
$$

where $\|\cdot\|_{2}$ denotes the Euclidean norm. Since, from (2.9), (2.12), one has

$$
Z_{i+1}=D^{i} Z_{i}+h B^{i}\left(I_{m}-h S^{i}\right)^{-1} g_{i},
$$

the inequality (3.4) implies

$$
\left\|D^{i}\right\|_{2} \leq 1, \quad i \geq 0
$$

and the assertion follows.

The previous theorem allows us immediately to state the following result about two of the most common VDC methods.

Corollary 3.3. The VDC method whose collocation parameters are the Gauss points is, on kernels of class $A$, locally stable in each $t_{i}$ and for each stepsize $h$.

Corollary 3.4. The Runge-Kutta method Radau IIA is, on kernels of class $A$, locally stable in each $t_{i}$ and for each stepsize $h$.

Now we wish to investigate the conditions for bounded propagation of isolated perturbations [9, p. 428], since it is known that local stability is only a necessary condition for this kind of stability.

Theorem 3.4. If the corresponding Runge-Kutta method is algebraically stable, then the VDC method involves, on kernels of class $A$, a bounded propagation of isolated perturbations, provided that $h<1 / \gamma\|W\|_{\infty}$, where $\gamma$ is given by (3.1) and $W$ by (1.8).

Proof. Denote by $\left\{v_{i}\right\}$ and $\left\{v_{i}^{*}\right\}$ the solution of (2.9) obtained for the inhomogeneous terms $\left\{\rho_{i}\right\}$ and $\left\{\rho_{i}^{*}\right\}$, respectively. Since, from the definition of an isolated perturbation, we have $\left\|\rho_{i}-\rho_{i}^{*}\right\|_{2} \leq \delta$ for $i=0, \ldots, r$, we get from (3.5) that

$$
\begin{aligned}
\left\|Z_{i+1}-Z_{i+1}^{*}\right\|_{2} \leq & \left\|D_{i}\right\|_{2}\left\|Z_{i}-Z_{i}^{*}\right\|_{2} \\
& +\left\|h B^{i}\left(I_{m}-h S^{i}\right)^{-1}-\left(h B^{i}\left(I_{m}-h S^{i}\right)^{-1}\right)^{*}\right\|_{2} \\
\leq & \left\|D_{i}\right\|_{2}\left\|Z_{i}-Z_{i}^{*}\right\|_{2}+\delta .
\end{aligned}
$$

Setting

$$
\Omega_{1}=\max _{0 \leq i \leq r}\left\{1+\sum_{k=0}^{i} \prod_{j=1}^{k}\left\|D^{i-j}\right\|_{2}\right\}
$$


we obtain from (3.7), (3.4)

$$
\left\|Z_{i+1}-Z_{i+1}^{*}\right\|_{2} \leq \Omega_{1} \delta, \quad i \geq 0 .
$$

Analogously, for the vector $U_{i+1}=\left[u_{i 1}, u_{i 2}, \ldots, u_{i m}\right]^{\mathrm{T}},(2.9)$ yields

$$
\left\|U_{i+1}-U_{i+1}^{*}\right\| \leq \Omega_{2} \delta, \quad i \leq r \text {, }
$$

where

$$
\Omega_{2}=\max _{0 \leq i \leq r}\left[1+\left\|\left(I_{m}-h S^{i}\right)^{-1} A^{i}\right\|_{2} \Omega_{1}\right],
$$

whereas, for $i>r$, from (2.9) and (3.8), observing that the hypothesis $h\|W\|_{\infty} \gamma$ $<1$ implies

$$
\left\|\left(I_{m}-h S^{i}\right)^{-1}\right\|_{\infty} \leq 1 /\left(1-h \gamma\|W\|_{\infty}\right),
$$

we obtain

$$
\left\|U_{i+1}-U_{i+1}^{*}\right\| \leq \Omega_{3} \delta, \quad i \geq r+1, \ldots,
$$

where

$$
\Omega_{3}=\sqrt{n} /\left(1-h \gamma\|W\|_{\infty}\right) \sup _{t \in\left[t_{0}, \infty\right)} \sum_{l=1}^{n}\left|a_{l}(t)\right| \Omega_{1} .
$$

Finally, from (1.2),

$$
\left|u\left(t_{i+1}\right)-u^{*}\left(t_{i+1}\right)\right| \leq\|L\|_{2}\left\|U_{i+1}-U_{i+1}^{*}\right\|,
$$

where $L$ is defined in (2.6). Therefore, putting

$$
\Omega^{*}=\max \left\{\Omega_{1}, \Omega_{2}, \Omega_{3},\|L\|_{2} \Omega_{2},\|L\|_{2} \Omega_{3}\right\},
$$

we get

$$
\left\|v_{i}-v_{i}^{*}\right\|_{2} \leq \Omega^{*} \delta, \quad i \geq 0
$$

as asserted.

\section{NUMERICAL EXPERIMENTS}

In this section we report on numerical results intended to show the reliability of the stability conditions previously derived.

We have chosen the following integral equation problems, whose solutions have, respectively, a constant, oscillating, and decreasing behavior:

(A) $y(t)=1+120 t-100\left(1-e^{-t}\right)+\int_{0}^{t}\left[100 e^{(s-t)}-120\right] y(s) d s, \quad t \in[0,20]$,

exact solution: $y(t)=1$;

$$
\begin{aligned}
y(t)= & \sin 10 t+480 / 101\left(\sin 10 t-10 \cos 10 t+10 e^{-t}\right)-50(\cos 10 t-1) \\
& +\int_{0}^{t}\left[500 e^{(s-t)}+480\right] y(s) d s, \quad t \in[0,20],
\end{aligned}
$$

exact solution: $y(t)=\sin 10 t$;

$$
y(t)=e^{-t}-3000(t+0.1) /(1+t)\left(e^{-2 t}-1\right)
$$

$$
-6000 \int_{0}^{t}(t+0.1) /(1+t) e^{-s} y(s) d s, \quad t \in[0,20],
$$

exact solution: $y(t)=e^{-t}$. 
Moreover, in order to test the reliability of the stability conditions in nonlinear problems, we consider the following equations:

$$
y(t)=t-1+2 e^{-t}+\int_{0}^{t}\left(2 e^{s-t}-1\right) y^{2}(s) d s, \quad t \in[0,40],
$$

exact solution: $y(t)=1$;

$$
y(t)=1+t+t^{2} / 2-\int_{0}^{t}(1+t-s) y^{2}(s) d s, \quad t \in[0,40],
$$

exact solution: $y(t)=1$.

As to the nonlinear problems, we apply the stability theorems to their linearized versions.

Problems (A) $-(\mathrm{E})$ have been solved with the following VDC methods:

(1) $m=2, c_{1}=0, c_{2}=1$;

(2a) $m=3, c_{1}=0, c_{2}=1 / 2, c_{3}=1$ (Lobatto points) with implicit discretization;

(2b) $m=3$ (Lobatto points) with fully implicit discretization;

(3a) $m=4, c_{1}=0.08858, c_{2}=0.40947, c_{3}=0.78766, c_{4}=1$ (Radau IIA points) with implicit discretization;

(3b) $m=4$ (Radau IIA points) with fully implicit discretization.

For the convolution problems (A), (B), (D), and (E), the application of the stability theorems derived in $\S \S 2$ and 3 requires the calculation of the roots of the polynomial (2.14), which in this case is of second degree. In virtue of Theorem 2.5, this calculation is made only in the first step. In problem $(\mathrm{C})$, the calculation of the root of the polynomial (2.14) whose degree, in this case, is one, must be made for every step. Of course, since the kernel is of class $A$, for the method (3a), this computation could be avoided in virtue of Theorem 3.3.

In Tables $1-5$ we report relative and absolute errors in selected points for the above collocation methods applied to the integral problems $(\mathrm{A})-(\mathrm{E})$. The quantities $X_{\min }$ and $X_{\max }$ are respectively the minimum and the maximum of the values assumed in the integration range by the maximum modulus root of the polynomial (2.14).

We observe that, in all cases, the VDC methods have a stable behavior every time the stability condition is satisfied. However, for problem (C), the numerical solution decreases more slowly than the true solution, and thus the relative error can be large; this is particularly true for the VDC methods (1) and (2). In some cases (method (1), problem (C), $h=0.1$; method (2a), problem (C), $h=0.5 ;$ method (3a), problem (A), $h=0.5$; methods (3a), (3b), problem (D), $h=0.05)$ the method has a stable behavior even if the stability condition is not satisfied; this is because the stability condition holds for the vector $v_{i}$ and not only for $u\left(t_{i}\right)$.

In other cases (for example method (1), problem (A), $h=0.25$; method (2a), problem (B), $h=0.5$; problem (D), $h=0.05$ and so on), the stability condition is not satisfied and the method is unstable.

Note that, for method (1) applied to problems (A) and (B), as expected, $X_{\max }$ is less than 1 if and only if the hypothesis of Theorem 3.3 holds.

Finally, we wish to stress that numerical results, more numerous than those reported here, show that the fully implicit discretization is more accurate than the implicit one; and the latter has the expected stable behavior in the cases covered by Theorem 3.3. 
TABLE 1

Collocation parameters: $c_{1}=0, c_{2}=1$

\begin{tabular}{|c|c|c|c|c|c|c|}
\hline Problem & h & t & Rel.Err. & Abs.Err. & $X_{\min }$ & $X_{\max }$ \\
\hline \multirow[t]{2}{*}{ A } & .25 & 20 & $\begin{array}{l}.70 \mathrm{E} 05 \\
.25 \mathrm{E} 12\end{array}$ & $\begin{array}{l}.70 \mathrm{E} 05 \\
.25 \mathrm{E} 12\end{array}$ & $.29 \mathrm{E} 01$ & $.29 \mathrm{E} 01$ \\
\hline & .1 & 10 & $\begin{array}{l}.48 \mathrm{E}-14 \\
.18 \mathrm{E}-13\end{array}$ & $\begin{array}{l}.48 \mathrm{E}-14 \\
.18 \mathrm{E}-13\end{array}$ & $.84 \mathrm{E} 00$ & $.84 \mathrm{E} 00$ \\
\hline \multirow[t]{2}{*}{$B$} & .1 & $\begin{array}{l}10 \\
20\end{array}$ & $\begin{array}{l}.54 \mathrm{E} 14 \\
.28 \mathrm{E} 28\end{array}$ & $\begin{array}{l}.27 \mathrm{E} 14 \\
.25 \mathrm{E} 28\end{array}$ & $.20 \mathrm{E} 01$ & $.20 \mathrm{E} 01$ \\
\hline & .05 & $\begin{array}{l}10 \\
20\end{array}$ & $\begin{array}{l}.47 \mathrm{E}-01 \\
.24 \mathrm{E}-01\end{array}$ & $\begin{array}{l}.23 \mathrm{E}-01 \\
.21 \mathrm{E}-01\end{array}$ & $.57 \mathrm{E} 00$ & $.57 \mathrm{E} 00$ \\
\hline \multirow[t]{2}{*}{$f$} & .1 & 20 & $\begin{array}{l}.17 \mathrm{E}-01 \\
.31 \mathrm{E} 03\end{array}$ & $\begin{array}{l}.77 \mathrm{E}-06 \\
.64 \mathrm{E}-06\end{array}$ & $.22 \mathrm{E}-01$ & $.10 \mathrm{E} 01$ \\
\hline & .06 & 20 & $\begin{array}{l}.62 \mathrm{E}-02 \\
.11 \mathrm{E} 03\end{array}$ & $\begin{array}{l}.27 \mathrm{E}-06 \\
.23 \mathrm{E}-06\end{array}$ & $.43 \mathrm{E}-02$ & $.99 \mathrm{E} 00$ \\
\hline \multirow[t]{2}{*}{ ח } & .15 & 40 & $.10 \mathrm{E} 06$ & $\begin{array}{l}.29 \mathrm{E} 00 \\
.10 \mathrm{E} 06\end{array}$ & $.13 \mathrm{E} 01$ & $.13 \mathrm{E} 01$ \\
\hline & .05 & 20 & $\begin{array}{l}.38 \mathrm{E}-01 \\
.37 \mathrm{E} 01\end{array}$ & $\begin{array}{l}.38 \mathrm{E}-01 \\
.37 \mathrm{E} \quad 01\end{array}$ & $.11 \mathrm{E} 01$ & $.11 \mathrm{E} 01$ \\
\hline & .25 & 20 & $\begin{array}{l}.00 \mathrm{E} 00 \\
.00 \mathrm{E} 00\end{array}$ & $\begin{array}{l}.00 \mathrm{E} 00 \\
.00 \mathrm{E} 00\end{array}$ & $.99 \mathrm{E} 00$ & $.99 \mathrm{E} 00$ \\
\hline & .1 & 20 & $.83 E-16$ & $\begin{array}{l}.47 \mathrm{E}-15 \\
.83 \mathrm{E}-16\end{array}$ & $.99 \mathrm{E} 00$ & $.99 \mathrm{E} 00$ \\
\hline
\end{tabular}


TABLE 2

Collocation parameters: $c_{1}=0, c_{2}=1 / 2, c_{3}=1$ (impl. discr.)

\begin{tabular}{|c|c|c|c|c|c|c|}
\hline Problem & $\mathbf{h}$ & $t$ & Rel.Err. & Abs.Err. & $\boldsymbol{X}_{\min }$ & $X_{\max }$ \\
\hline \multirow{2}{*}{$A$} & .5 & 20 & $\begin{array}{l}.30 \mathrm{E} 10 \\
.10 \mathrm{E} 22\end{array}$ & $\begin{array}{l}.30 \mathrm{E} 05 \\
.10 \mathrm{E} 22\end{array}$ & $.99 \mathrm{E} 01$ & $.99 \mathrm{E} 01$ \\
\hline & .25 & 20 & $\begin{array}{l}.14 \mathrm{E}-02 \\
.14 \mathrm{E}-02\end{array}$ & $\begin{array}{l}.14 \mathrm{E}-02 \\
.14 \mathrm{E}-02\end{array}$ & $.65 \mathrm{E} 00$ & $.65 \mathrm{E} 00$ \\
\hline \multirow{2}{*}{$B$} & .5 & 20 & $\begin{array}{l}.16 \mathrm{E} 19 \\
\text { overflow }\end{array}$ & $\begin{array}{c}.83 \mathrm{E} 18 \\
\text { overflow }\end{array}$ & $.12 \mathrm{E} 03$ & $.12 \mathrm{E} 03$ \\
\hline & .1 & 20 & $\begin{array}{l}.81 \mathrm{E}-01 \\
.53 \mathrm{E}-01\end{array}$ & $\begin{array}{l}.41 \mathrm{E}-01 \\
.46 \mathrm{E}-01\end{array}$ & $.27 \mathrm{E} 00$ & $.27 \mathrm{E} 00$ \\
\hline \multirow{2}{*}{$C$} & .5 & 20 & $\begin{array}{l}.10 \mathrm{E} 01 \\
.18 \mathrm{E} 05\end{array}$ & $\begin{array}{l}.46 \mathrm{E}-04 \\
.38 \mathrm{E}-04\end{array}$ & $.10 \mathrm{E}-00$ & $.14 \mathrm{E} 01$ \\
\hline & .1 & 20 & $\begin{array}{l}.11 \mathrm{E}-04 \\
.21 \mathrm{E} 00\end{array}$ & $\begin{array}{l}.53 \mathrm{E}-09 \\
.43 \mathrm{E}-09\end{array}$ & $.79 \mathrm{E}-01$ & $.99 \mathrm{E} 00$ \\
\hline \multirow{2}{*}{$\theta$} & 5 & $18^{\circ}$ & $\begin{array}{l}.49 \mathrm{E}-01 \\
.61 \mathrm{E} 01\end{array}$ & $\begin{array}{l}.49 \mathrm{E}-01 \\
.61 \mathrm{E} 06\end{array}$ & $.26 \mathrm{E} 01$ & $.26 \mathrm{E} 01$ \\
\hline & .05 & 20 & $\begin{array}{l}.44 \mathrm{E}-05 \\
.57 \mathrm{E}-03\end{array}$ & $\begin{array}{l}.44 \mathrm{E}-05 \\
.57 \mathrm{E}-03\end{array}$ & $.11 \mathrm{E} 01$ & $.11 \mathrm{E} 01$ \\
\hline \multirow{2}{*}{$E$} & .5 & 10 & $\begin{array}{l}.27 \mathrm{E}-15 \\
.51 \mathrm{E}-14\end{array}$ & $\begin{array}{l}.27 \mathrm{E}-15 \\
.51 \mathrm{E}-14\end{array}$ & $.97 \mathrm{E} 00$ & $.97 \mathrm{E} 00$ \\
\hline & .1 & 10 & $\begin{array}{l}.27 \mathrm{E}-14 \\
.17 \mathrm{E}-13\end{array}$ & $\begin{array}{l}.27 \mathrm{E}-14 \\
.17 \mathrm{E}-13\end{array}$ & $.99 \mathrm{E} 00$ & $.99 \mathrm{E} 00$ \\
\hline
\end{tabular}

*In the next step, the nonlinear system of the collocation equations cannot be solved. 
TABLE 3

Collocation parameters: $c_{1}=0, c_{2}=1 / 2, c_{3}=1$ (fully impl. discr.)

\begin{tabular}{|c|c|c|c|c|c|c|}
\hline Problem & $h$ & $t$ & Rel.Err. & Abs.Err. & $X_{\min }$ & $X_{\max }$ \\
\hline \multirow{2}{*}{ A } & .5 & 20 & $\begin{array}{l}.75 \mathrm{E}-03 \\
.75 \mathrm{E}-03\end{array}$ & $\begin{array}{l}.75 \mathrm{E}-03 \\
.75 \mathrm{E}-03\end{array}$ & $.55 \mathrm{E} 00$ & $.55 \mathrm{E} 00$ \\
\hline & .1 & 20 & $\begin{array}{l}.10 \mathrm{E}-06 \\
.10 \mathrm{E}-06\end{array}$ & $\begin{array}{l}.10 \mathrm{E}-06 \\
.10 \mathrm{E}-06\end{array}$ & $.95 \mathrm{E} 00$ & $.95 \mathrm{E} 00$ \\
\hline \multirow{2}{*}{$B$} & .5 & 20 & $\begin{array}{l}.21 \mathrm{E} 10 \\
.39 \mathrm{E} 19\end{array}$ & $\begin{array}{l}.10 \mathrm{E} 10 \\
.34 \mathrm{E} 19\end{array}$ & $.12 \mathrm{E} 03$ & $.29 \mathrm{E} 02$ \\
\hline & .05 & 20 & $\begin{array}{l}.30 \mathrm{E}-03 \\
.54 \mathrm{E}-04\end{array}$ & $\begin{array}{l}.10 \mathrm{E}-02 \\
.47 \mathrm{E}-04\end{array}$ & $.87 \mathrm{E} 00$ & $.87 \mathrm{E} 00$ \\
\hline \multirow{2}{*}{6} & .5 & 20 & $\begin{array}{l}.69 \mathrm{E}-03 \\
.13 \mathrm{E} 02 \\
\end{array}$ & $\begin{array}{l}.31 \mathrm{E}-07 \\
.27 \mathrm{E}-07\end{array}$ & $.74 \mathrm{E}-01$ & $.99 \mathrm{E} 00$ \\
\hline & .06 & 20 & $\begin{array}{l}.14 \mathrm{E}-06 \\
.27 \mathrm{E}-02\end{array}$ & $\begin{array}{l}.65 \mathrm{E}-11 \\
.55 \mathrm{E}-11\end{array}$ & $.72 \mathrm{E}-01$ & $.99 \mathrm{E} 00$ \\
\hline \multirow[t]{2}{*}{$\theta$} & .5 & 40 & $\begin{array}{l}.16 \mathrm{E}-02 \\
.25 \mathrm{E} 04\end{array}$ & $\begin{array}{l}.16 \mathrm{E}-02 \\
.25 \mathrm{E} 04\end{array}$ & $.26 \mathrm{E} 01$ & $.26 \mathrm{E} 01$ \\
\hline & .05 & 20 & $\begin{array}{l}.28 \mathrm{E}-06 \\
.68 \mathrm{E}-04\end{array}$ & $\begin{array}{l}.28 \mathrm{E}-06 \\
.68 \mathrm{E}-04\end{array}$ & $.11 \mathrm{E} 01$ & $.11 \mathrm{E} 01$ \\
\hline \multirow[t]{2}{*}{$E$} & .5 & 20 & $\begin{array}{l}.10 \mathrm{E}-14 \\
.17 \mathrm{E}-14 \\
\end{array}$ & $\begin{array}{l}.10 \mathrm{E}-14 \\
.17 \mathrm{E}-14\end{array}$ & $.97 \mathrm{E} 00$ & $.97 \mathrm{E} 00$ \\
\hline & .1 & 20 & $\begin{array}{l}.27 \mathrm{E}-14 \\
.17 \mathrm{E}-13\end{array}$ & $\begin{array}{l}.27 \mathrm{E}-14 \\
.17 \mathrm{E}-13\end{array}$ & $.99 \mathrm{E} 00$ & $.99 \mathrm{E} 00$ \\
\hline
\end{tabular}


TABLE 4

Collocation parameters: $c_{1}=.08858, c_{2}=.40947, c_{3}=.78766$, $c_{4}=1$ (impl. discr.)

\begin{tabular}{|c|c|c|c|c|c|c|}
\hline Problem & h & $\mathrm{t}$ & Rel.Err. & Abs.Err. & $X_{\min }$ & $X_{\max }$ \\
\hline & .5 & 20 & $\begin{array}{l}.36 \mathrm{E}-03 \\
.36 \mathrm{E}-03\end{array}$ & $\begin{array}{l}.36 \mathrm{E}-03 \\
.36 \mathrm{E}-03\end{array}$ & $.14 \mathrm{E} 01$ & $.14 \mathrm{E} 01$ \\
\hline & .1 & 20 & $\begin{array}{l}.28 \mathrm{E}-08 \\
.28 \mathrm{E}-08\end{array}$ & $\begin{array}{l}.28 \mathrm{E}-08 \\
.24 \mathrm{E}-08\end{array}$ & $.95 \mathrm{E} 00$ & $.95 \mathrm{E} 00$ \\
\hline & .5 & $\begin{array}{l}10 \\
20\end{array}$ & $\begin{array}{l}.17 \mathrm{E} 01 \\
.11 \mathrm{E} 01\end{array}$ & $\begin{array}{l}.86 \mathrm{E} 00 \\
.10 \mathrm{E} 01\end{array}$ & $.99 \mathrm{E} 00$ & $.99 \mathrm{E} 00$ \\
\hline & .05 & 20 & $\begin{array}{l}.76 \mathrm{E}-06 \\
.38 \mathrm{E}-06\end{array}$ & $\begin{array}{l}.38 \mathrm{E}-06 \\
.33 \mathrm{E}-06\end{array}$ & $.87 \mathrm{E} 00$ & $.87 \mathrm{E} 00$ \\
\hline & .5 & 20 & $\begin{array}{l}.36 \mathrm{E}-05 \\
.65 \mathrm{E}-01\end{array}$ & $\begin{array}{l}.16 \mathrm{E}-09 \\
.13 \mathrm{E}-09\end{array}$ & $.30 \mathrm{E}-02$ & $.99 \mathrm{E} 00$ \\
\hline & .06 & 20 & $\begin{array}{l}.49 \mathrm{E}-08 \\
.57 \mathrm{E}-05\end{array}$ & $\begin{array}{l}.22 \mathrm{E}-12 \\
.11 \mathrm{E}-13\end{array}$ & $.90 \mathrm{E}-03$ & $.99 \mathrm{E} 00$ \\
\hline & .5 & $35^{*}$ & $\begin{array}{l}.11-05 \\
.29 \mathrm{E} 01\end{array}$ & $\begin{array}{l}.11 \mathrm{E}-05 \\
.20 \mathrm{E} 01 \\
\end{array}$ & $.26 \mathrm{E} 01$ & $.26 \mathrm{E} 01$ \\
\hline & .05 & 20 & $\begin{array}{l}.16 \mathrm{E}-10 \\
.39 \mathrm{E}-08\end{array}$ & $\begin{array}{l}.16 \mathrm{E}-10 \\
.39 \mathrm{E}-08\end{array}$ & $.11 \mathrm{E} 01$ & $.11 \mathrm{E} 01$ \\
\hline & .5 & 10 & $\begin{array}{l}.44 \mathrm{E}-15 \\
.41 \mathrm{E}-14\end{array}$ & $\begin{array}{l}.44 \mathrm{E}-15 \\
.41 \mathrm{E}-14\end{array}$ & $.97 \mathrm{E} 00$ & $.97 \mathrm{E} 00$ \\
\hline & .1 & 20 & $\begin{array}{l}.44 \mathrm{E}-15 \\
.54 \mathrm{E}-14\end{array}$ & $\begin{array}{l}.44 \mathrm{E}-15 \\
.54 \mathrm{E}-14\end{array}$ & $.99 \mathrm{E} 00$ & $.99 \mathrm{E} 00$ \\
\hline
\end{tabular}

*In the next step, the nonlinear system of the collocation equations cannot be solved. 
TABLE 5

Collocation parameters: $c_{1}=.08858, c_{2}=.40947, c_{3}=.78766$, $c_{4}=1$ (fully impl. discr.)

\begin{tabular}{|c|c|c|c|c|c|c|}
\hline Problem & $\mathrm{h}$ & $\mathbf{t}$ & Rel.Err. & Abs.Err. & $X_{\min }$ & $X_{\max }$ \\
\hline \multirow{2}{*}{ A } & .5 & 20 & $\begin{array}{l}.12 \mathrm{E}-07 \\
.12 \mathrm{E}-07\end{array}$ & $\begin{array}{l}.12 \mathrm{E}-07 \\
.12 \mathrm{E}-07\end{array}$ & $.24 \mathrm{E} 00$ & $.24 \mathrm{E} 00$ \\
\hline & .1 & 20 & $\begin{array}{l}.63 \mathrm{E}-11 \\
.64 \mathrm{E}-11\end{array}$ & $\begin{array}{l}.63 \mathrm{E}-11 \\
.64 \mathrm{E}-11\end{array}$ & $.95 \mathrm{E} 00$ & $.95 \mathrm{E} 00$ \\
\hline \multirow{2}{*}{$B$} & .5 & 20 & $\begin{array}{l}.43 \mathrm{E}-02 \\
.19 \mathrm{E} 00\end{array}$ & $\begin{array}{l}.22 \mathrm{E}-02 \\
.17 \mathrm{E} 00\end{array}$ & $.17 \mathrm{E} 01$ & $.17 \mathrm{E} 01$ \\
\hline & .05 & 20 & $\begin{array}{l}.94 \mathrm{E}-07 \\
.54 \mathrm{E}-07 \\
\end{array}$ & $\begin{array}{l}.51 \mathrm{E}-07 \\
.54 \mathrm{E}-07\end{array}$ & $.87 \mathrm{E} 00$ & $.87 \mathrm{E} 00$ \\
\hline \multirow[t]{2}{*}{$C$} & .5 & 20 & $\begin{array}{l}.12 \mathrm{E}-06 \\
.19 \mathrm{E}-02\end{array}$ & $\begin{array}{l}.57 \mathrm{E}-11 \\
.40 \mathrm{E}-11\end{array}$ & $.34 \mathrm{E}-02$ & $.99 \mathrm{E} 00$ \\
\hline & .06 & 20 & $\begin{array}{l}.49 \mathrm{E}-08 \\
.57 \mathrm{E}-05\end{array}$ & $\begin{array}{l}.22 \mathrm{E}-12 \\
.11 \mathrm{E}-13\end{array}$ & $.61 \mathrm{E}-03$ & $.99 \mathrm{E} 00$ \\
\hline \multirow[t]{2}{*}{ I } & .5 & 40 & $\begin{array}{l}.94-07 \\
.63 \mathrm{E} 00\end{array}$ & $\begin{array}{l}.94 \mathrm{E}-07 \\
.63 \mathrm{E} 00\end{array}$ & $.26 \mathrm{E} 01$ & $.26 \mathrm{E} 01$ \\
\hline & .05 & 20 & $\begin{array}{l}.14 \mathrm{E}-10 \\
.35 \mathrm{E}-08 \\
\end{array}$ & $\begin{array}{l}.14 \mathrm{E}-10 \\
.35 \mathrm{E}-08\end{array}$ & $.11 \mathrm{E} 01$ & $.11 \mathrm{E} 01$ \\
\hline \multirow[t]{2}{*}{$F$} & .5 & 20 & $\begin{array}{l}.55 \mathrm{E}-16 \\
.21 \mathrm{E}-14\end{array}$ & $\begin{array}{l}.55 \mathrm{E}-16 \\
.21 \mathrm{E}-14\end{array}$ & $.97 \mathrm{E} 00$ & $.97 \mathrm{E} 00$ \\
\hline & .1 & 10 & $\begin{array}{l}.11 \mathrm{E}-14 \\
.11 \mathrm{E}-13\end{array}$ & $\begin{array}{l}.11 \mathrm{E}-14 \\
.11 \mathrm{E}-13\end{array}$ & $.99 \mathrm{E} 00$ & $.99 \mathrm{E} 00$ \\
\hline
\end{tabular}




\section{BIBLIOGRAPHY}

1. S. Amini, On the stability of Volterra integral equations with separable kernels, Appl. Anal. 24 (1987), 241-251.

2. S. Amini, C. T. H. Baker, P. J. van der Houwen, and P. H. M. Wolkenfelt, Stability analysis of numerical methods for Volterra integral equations with polynomial convolution kernels, $\mathrm{J}$. Integral Equations 5 (1983), 73-92.

3. C. T. H. Baker, Structure of recurrence relations in the study of stability in the numerical treatment of Volterra integral and integro-differential equations, J. Integral Equations 2 (1980), 11-29.

4. J. G. Blom and H. Brunner, The numerical solution of nonlinear Volterra integral equations of the second kind by collocation and iterated collocation methods, SIAM J. Sci. Statist. Comput. 8 (1987), 806-830.

5. J. M. Bownds and J. M. Cushing, Some stability criteria for linear systems of Volterra integral equations, Funkcial. Ekvac. 15 (1972), 101-117.

6. H. Brunner, Superconvergence in collocation and implicit Runge-Kutta methods for Volterratype integral equations of the second kind, Numerical Treatment of Integral Equations (J. Albrecht and L. Collatz, eds.), Internat. Ser. Numer. Math., vol. 53, Birkhäuser, Basel, 1980 , pp. 54-72.

7. __ Collocation methods for one-dimensional Fredholm and Volterra integral equations, The State of the Art in Numerical Analysis (A. Iserles and M. J. D. Powell, eds.), Clarendon Press, Oxford, 1987, pp. 563-600.

8. H. Brunner and S. P. Nørsett, Superconvergence of collocation methods for Volterra and Abel integral equations of the second kind, Numer. Math. 36 (1981), 347-358.

9. H. Brunner and P. J. van der Houwen, The numerical solution of Volterra equations, CWI Monograph, North-Holland, 1986.

10. M. R. Crisci, E. Russo, and A. Vecchio, On the stability of the collocation methods for the numerical solution of the second kind Volterra integral equation, BIT 29 (1989), 258-269.

11. _ On the stability of the one-step exact collocation method for the second kind Volterra integral equation with degenerate kernel, Computing 40 (1988), 315-328.

12. K. Dekker and J. G. Verwer, Stability of Runge-Kutta methods for stiff nonlinear differential equations, CWI Monograph, no. 2, North-Holland, Amsterdam, 1984.

13. F. de Hoog and R. Weiss, Implicit Runge-Kutta methods for second kind Volterra integral equations, Numer. Math. 23 (1975), 199-213.

14. P. J. van der Houwen, Stability results for discrete Volterra equations, Report NW 149/83, Centre for Mathematics and Computer Science, Amsterdam, 1983.

15. P. J. van der Houwen and P. H. M. Wolkenfelt, On the stability of multistep formulas for Volterra integral equations of the second kind, Computing 24 (1980), 341-347.

(M. R. Crisci and E. Russo) Dipar timento di Matematica e Applicazioni, Università degli Studi di Napoli, Via Mezzocannone, 8, I-80134 Napoli, Italy

(A. Vecchio) Istituto per Applicazioni della Matematica, Consiglio Nazionale delle Ricerche, Via P. CASTEllino, 111, 80131 Napoli, Italy

E-mail address, A. Vecchio: iam\%areana@icnucevx.cnuce.cnr.it 